
ERYTHEMATOSUS CLASSIFICATION CRITERIA

M. Aringer ${ }^{1}$, K.H. Costenbader ${ }^{2}$, R. Brinks ${ }^{3}$, D. Boumpas ${ }^{4}$, D. Daikh ${ }^{5}$, D. Jayne ${ }^{6}$, D. Kamen ${ }^{7}$, M. Mosca ${ }^{8}$, R. Ramsey-Goldman ${ }^{9}$, J.S. Smolen ${ }^{10}$, D. Wofsy ${ }^{5}$, B. Diamond ${ }^{11}$, S. Jacobsen ${ }^{12}$, W.J. McCune ${ }^{13}$, G. Ruiz-Irastorza ${ }^{14}$, M. Schneider ${ }^{15}$, M.B. Urowitz ${ }^{16}$, G. Bertsias ${ }^{17}$, B. Hoyer ${ }^{18}$, N. Leuchten ${ }^{1}$, C. Tani ${ }^{8}$, S. Tedeschi ${ }^{2}$, Z. Touma ${ }^{16}$, B. Anic ${ }^{19}$, F. Assan ${ }^{20}$, T.M. Chan ${ }^{21}$, A.E. Clarke ${ }^{22}$, M.K. Crow ${ }^{23}$, L. Czírják ${ }^{24}$, A. Doria ${ }^{25}$, W. Graninger ${ }^{26}$, S. Hasni ${ }^{27}$, P. Izmirly ${ }^{28}$, M. Jung ${ }^{22}$, B. Kiss ${ }^{24}$, X. Mariette ${ }^{20}$, I. Padjen ${ }^{19}$, J.M. Pego-Reigosa ${ }^{29}$, J. Romero-Díaz ${ }^{30}$ I. Rúa-Figueroa ${ }^{31}$, R. Seror ${ }^{20}$, G. Stummvoll ${ }^{10}$, Y. Tanaka $^{32}$, M. Tektonidou ${ }^{4}$, C. Vasconcelos ${ }^{33}$, E. Vital ${ }^{34}$, D.J. Wallace ${ }^{35}$, S. Yavuz ${ }^{36}$, R.P. Naden ${ }^{37}$, T. Dörner ${ }^{38}$, S.R. Johnson ${ }^{16}$. ${ }^{1}$ TU Dresden, Dresden, Germany; ${ }^{2}$ Harvard Medical School, Boston, MA, USA; ${ }^{3}$ Hiller Center for Research in Rheumatology, Düsseldorf, Germany; ${ }^{4}$ University of Athens, Athens, Greece; ${ }^{5}$ UCSF, San Francisco, CA, USA; ${ }^{6}$ University of Cambridge, Cambridge, UK; ${ }^{7}$ MUSC, Charleston, SC, USA; ${ }^{8}$ University of Pisa, Pisa, Italy; ${ }^{9}$ Northwestern University, Chicago, IL, USA; ${ }^{10}$ Medical University of Vienna, Vienna, Austria; ${ }^{11}$ Feinstein Institute, Manhasset, NY, USA; ${ }^{12}$ Rigshospitalet, Copenhagen, Denmark; ${ }^{13}$ University of Michigan, Ann Arbor, MI, USA; ${ }^{4}$ UPV/EHU, Bizkaia, Spain; ${ }^{15}$ Universität Düsseldorf, Düsseldorf, Germany; ${ }^{16}$ University of Toronto, Toronto, Canada; ${ }^{17}$ University of Crete, Heraklion, Greece; ${ }^{18} \mathrm{UKSH}$, Kiel, Germany; ${ }^{19}$ University Hospital, Zagreb, Croatia; ${ }^{20}$ Université Paris Sud, Paris, France; ${ }^{21}$ University of Hong Kong, Hong Kong, China; ${ }^{22}$ University of Calgary, Calgary, Canada; ${ }^{23}$ HSS, New York, NY, USA $;{ }^{24}$ University of Pécs, Pécs, Hungary;

${ }^{25}$ University of Padova, Padova, Italy; ${ }^{26}$ Medical University of Graz, Graz, Austria; ${ }^{27}$ NIAMS, NIH, Bethesda, MD; ${ }^{28} \mathrm{NYU}$, New York, NY, USA; ${ }^{29}$ University of Vigo, Vigo, Spain; ${ }^{30}$ INCMNSZ, Mexico City, Mexico; ${ }^{31}$ Hospital Dr Negrin, Las Palmas, Spain; ${ }^{32}$ University of Occupational and Environmental Health, Kitakyushu, Japan; ${ }^{33}$ University of Porto, Porto, Portugal; ${ }^{34}$ University of Leeds, Leeds, UK; ${ }^{35}$ CedarsSinai, Los Angeles, CA, USA; ${ }^{36}$ Istanbul Bilim University, Istanbul, Turkey, ${ }^{37} \mathrm{New}$ Zealand Ministry of Health, Auckland, New Zealand; ${ }^{38}$ Charité University, Berlin, Germany

Background: This 4 phase project ${ }^{1}$ jointly supported by EULAR and ACR has led to draft criteria. ${ }^{2}$

Objectives: To simplify and validate the new criteria in a large international cohort.

Methods: 23 expert centres each contributed up to 100 patients with SLE and with non-SLE diagnoses. Diagnoses were verified by 3 independent reviewers for 1,193 SLE and 1059 non-SLE patients. 500 randomly selected SLE and non-SLE patients formed the derivation cohort and the remainder the validation cohort.

Results: The criteria were fine-tuned and simplified, using ANA of $\geq 1: 80$ as entry criterion and a classification threshold of 10 .

\begin{tabular}{|c|c|c|c|c|c|c|}
\hline Renal & Class III/IV nephritis & 10 & $\begin{array}{c}\text { Class II/V } \\
\text { nephritis }\end{array}$ & 8 & $\begin{array}{c}\text { Proteinuria } \geq 0.5 \mathrm{~g} / \\
\text { day }\end{array}$ & 4 \\
\hline $\begin{array}{l}\text { Specific } \\
\text { antibodies }\end{array}$ & $\begin{array}{l}\text { Anti-Sm or } \\
\text { Anti-dsDNA }\end{array}$ & 6 & & & & \\
\hline $\begin{array}{l}\text { Muco- } \\
\text { cutaneous }\end{array}$ & ACLE & 6 & $\begin{array}{l}\text { SCLE or } \\
\text { DLE }\end{array}$ & 4 & $\begin{array}{l}\text { Alopecia or oral } \\
\text { ulcers }\end{array}$ & 2 \\
\hline Serosa & Acute pericarditis & 6 & Effusion & 5 & & \\
\hline $\begin{array}{l}\text { Musculo- } \\
\text { skeletal }\end{array}$ & Arthritis & 6 & & & & \\
\hline CNS & Seizures & 5 & Psychosis & 3 & Delirium & 2 \\
\hline Blood & $\begin{array}{l}\text { Autoimmune hemolysis } \\
\text { or thrombocytopenia }\end{array}$ & 4 & Leukopenia & 3 & & \\
\hline Complement & Low C3 and C4 & 4 & $\begin{array}{l}\text { Low C3 or } \\
\quad \text { C4 }\end{array}$ & 3 & & \\
\hline $\begin{array}{l}\text { Anti- } \\
\text { phospholipid }\end{array}$ & $\begin{array}{c}\text { Anti-Cardiolipin or anti- } \beta \\
\text { 2-GPI or lupus } \\
\text { anticoagulant }\end{array}$ & 2 & & & & \\
\hline Constitutional & Fever & 2 & & & & \\
\hline
\end{tabular}

Sensitivity was close to the SLICC 2012 criteria, specificity maintained at the level of the ACR 1997 criteria. This performance was independently confirmed in the validation cohort.

\begin{tabular}{lccc}
\hline & $\begin{array}{c}\text { ACR } 1997 \\
\text { criteria }\end{array}$ & $\begin{array}{c}\text { SLICC } \\
\text { criteria }\end{array}$ & $\begin{array}{c}\text { New } \\
\text { criteria }\end{array}$ \\
\hline $\begin{array}{l}\text { Derivation } \\
\text { Sensitivity }\end{array}$ & 84.63 & 96.81 & 98.00 \\
$\begin{array}{l}\text { Specificity } \\
\text { Validation }\end{array}$ & 95.20 & 90.00 & 96.40 \\
Sensitivity & & & 96.12 \\
Specificity & 82.76 & 96.70 & 93.38 \\
\hline
\end{tabular}

Conclusions: The new criteria developed with EULAR/ACR support achieved sensitivity close to the SLICC criteria, while maintaining the specificity of the ACR criteria.

REFERENCES:

[1] Aringer, et al. Ann Rheum Dis 2017;76(S2):4.

[2] Tedeschi, et al. Ann Rheum Dis 2017;76(S2):50.

Disclosure of Interest: None declared

DOI: 10.1136/annrheumdis-2018-eular.3679

\title{
OP0021 DRAFT CLASSIFICATION CRITERIA FOR THE ANCA
} ASSOCIATED VASCULITIDES

J.C. Robson ${ }^{1}$, P.C. Grayson ${ }^{2}$, C. Ponte ${ }^{3}$, R. Suppiah ${ }^{4}$, A. Craven ${ }^{5}$, S. Khalid ${ }^{5}$, A. Judge ${ }^{5}$, A. Hutchings ${ }^{6}$, D. Gray ${ }^{5}$, J. Rosa ${ }^{5}$, J. Barrett ${ }^{5}$, R.A. Watts ${ }^{5}$, P. A. Merkel ${ }^{7}$, R. Luqmani ${ }^{5} .{ }^{1}$ Rheumatology Unit, Faculty of Health and Applied Sciences, University of the West of England, Bristol, Bristol, UK; ${ }^{2}$ NIAMS/National Institutes of Health, Bethesda, USA; ${ }^{3}$ Lisbon Academic Medical Centre, Lisbon, Portugal; ${ }^{4}$ Auckland District Health Board, Auckland, New Zealand; ${ }^{5}$ University of Oxford, Oxford; ${ }^{6}$ London School of Hygiene and Tropical Medicine, London, UK; ${ }^{7}$ University of Pennsylvania, Philadelphia, USA

Background: Classification criteria for the ANCA-associated vasculitides (AAVs) were developed in the 1980s prior to the use of ANCA testing and newer imaging techniques. The Diagnostic and Classification of the Systemic Vasculitides (DCVAS) study is an international project to update classification criteria for the systemic vasculitides.

Objectives: Development of draft classification criteria for Granulomatosis with Polyangiitis (GPA), Microscopic Polyangiitis (MPA) and Eosinophilic Granulomatosis with Polyangiitis (EGPA)

Methods: Three phases: 1) Expert panel review of cases to identify gold standard set of new cases of small vessel vasculitis; 2 ) Item reduction of $>8000$ individual DCVAS items using data-driven and consensus methodology; 3) Lasso logistic regression models within each development set comparing each of the AAV types to other small and medium vessel vasculitides. Final criteria derived through clinical consensus, tested in validation set. The classification project has received financial support from the ACR and EULAR.

Results: The expert review process approved 2072/2871 (72\%) of physician diagnosed DCVAS cases, including [724 GPA, 291 MPA, 226 EGPA, 51 polyarteritis nodose (PAN), 220 other small vessel disease (SVV)]. Data driven and expert consensus resulted in 91 items retained. Draft criteria, and sensitivity and specificity in table 1

Abstract OP0021 - Table 1. Draft classification criteria for the ANCA-associated vasculitides. ${ }^{*}$ Cartilagenous involvement: Inflamed ear or nose cartilage or hoarse voice/ stridor, endobronchial involvement or saddle nose deformity

\begin{tabular}{lcc}
\hline $\begin{array}{l}\text { Granulomatosis with } \\
\text { polyangiitis (GPA) }\end{array}$ & $\begin{array}{c}\text { Microscopic polyangiitis } \\
\text { (MPA) }\end{array}$ & $\begin{array}{c}\text { Eosinophilic } \\
\text { granulomatosis with } \\
\text { polyangitis (EGPA) }\end{array}$ \\
\hline $\begin{array}{l}\text { Blood nasal discharge, ulcers, } \\
\text { crusting, congestion or }\end{array}$ & $\begin{array}{c}\text { Pauci-immune } \\
\text { glomerulonephritis }+3\end{array}$ & $\begin{array}{c}\text { Obstructive airways } \\
\text { diseases+3 }\end{array}$
\end{tabular}

blockage, or septal defect/

perforation +3

Cartilagenous involvement ${ }^{\star}+2$

Bloody nasal discharge,

Nasal polyps+3 ulcers, crusting, congestion or blockage, septal defect/ perforation -3

Conductive or sensorineural hearing loss +1

Pauci-immune

glomerulonephritis +1 cANCA or PR3-antibody +5

pANCA or MPO-antibody positive +6

Fibrosis or ILD on chest imaging +3

cANCA or PR3-antibody $-1 \quad$ Extravascular eosinophilic predominant inflammation/ eosinophils in bone marrow $+2$

pANCA or MPO-antibody $-1 \quad$ Eosinophil count $\geq 1 \times 10^{9} / \mathrm{L}-4$

Eosinophil count $\geq 1 \times 10^{9} / \mathrm{L}-4$ PR3-antibody

Granuloma, extravascular granulomatous inflammation, or giant cells on biopsy +2 Nodules, mass, cavitation on chest imaging +2

Inflammation, consolidation, or effusion of the nasal/ paranasal sinuses on imaging $+1$

Total score of $\geq 5$ is needed for classification Sensitivity $93 \%$, Specificity $94 \%$ Total score of $\geq 6$ is needed
for classification Sensitivity $87 \%$, Specificity 96\%)

Microscopic haematuria - 
Conclusions: Draft classification criteria for GPA, MPA and EGPA have been created which reflect current practice and have good sensitivity and specificity. Acknowledgements: DCVAS sites and expert panel members Disclosure of Interest: None declared DOI: 10.1136/annrheumdis-2018-eular.2892

\section{WEDNESDAY, 13 JUNE 2018}

\section{From NSAIDs to bDMARDs in SpA: what is new?}

\section{OP0022 IS A PRIMARY GOOD RESPONSE TO NSAIDS PREDICTIVE OF THE SUBSEQUENT RESPONSE TO THE FIRST TNF INHIBITOR IN PATIENTS WITH RECENT AXIAL SPONDYLOARTHRITIS?}

L. Couvaras ${ }^{1}$, D. Wendling ${ }^{2}$, V. Pauly ${ }^{3}$, V. Pradel ${ }^{3}$, A. Moltó $^{4}$, P. Lafforgue ${ }^{1}$, T. Pham ${ }^{5} .{ }^{1}$ Aix-Marseille University, APHM, Marseille; ${ }^{2}$ Bourgogne-Franche-Comté University, CHRU Besançon, Besançon; ${ }^{3} \mathrm{APHM}$, Marseille; ${ }^{4}$ Cochin Hospital, Paris; ${ }^{5}$ Aix-Marseille University, APHM, Marseille, France

Background: Good response to NSAIDs is a SpA feature included in classification criteria for axial spondyloarthritis $(\mathrm{axSpA})$. Among patients eligible for a TNF inhibitor (TNFi), some patients may have never responded to NSAIDs (non-responders to NSAIDs) while others initially responded (responders to NSAIDs) but have secondly escaped and need to be treated with biologics.

Objectives: Our aim was to determine if the initial response to NSAIDs is an independent predictive factor of a subsequent good response to the first TNFi in axSpA.

Methods: Patients: Patients from the prospective observational DESIR cohort of early axSpA cohort who started a TNFi over the 5 years of follow-up. NSAIDs response and TNFi response definitions

NSAIDs response was defined by the item 'good response to NSAIDs according to Amor's criteria' at the inclusion visit. TNFi response was defined by the BASDAI50 response between the 'baseline' visit (last cohort visit before TNFi initiation) and the 'follow-up' visit (visit taking place after at least 8 weeks of TNFi treatment).

Analysis: We compared the characteristics of the NSAIDs responder to the nonresponders and their response to the first TNFi.

We performed a multivariate logistic regression modelling the impact of an NSAID response to the TNFi response. We included known predictive factors of TNFi response in this model (age, gender, HLAB-B27, activity of the disease [ASDASCRP], CRP, X-ray and MRI sacroiliitis). To account for selection bias and for confirmation purpose, we applied a propensity score with Inverse Probability Weighting (IPW) method to predict TNFi response (SAS, version 9.2).

Results: Among the 708 patients of the cohort, 236 were included in the analysis. At the inclusion, the main characteristics were the following: $106(44.7 \%)$ males mean age $33.8 \pm 3.9$ years, mean BASDAI 54.5 \pm 17.3 and 202 (85.6\%) were NSAIDs responders.

The NSAIDs responder and non-responder groups were comparable at $\mathrm{M0}$ except for HLA-B27 positive status: $59.9 \%$ vs $40.1 \%, p=0,041$, CRP level: 13.4 $\pm 20.3 \mathrm{mg} / \mathrm{L}$ vs $6.3 \pm 6.6 \mathrm{mg} / \mathrm{L}, \mathrm{p}=0,027$, history of psoriasis: $17.8 \%$ vs $35.3 \%$, $\mathrm{p}=0.001$ and BASDAl: $53.0 \pm 18.1$ vs $61.8 \pm 13.2, \mathrm{p}=0,001$, in responder and nonresponder patients, respectively.

The percentage of TNFi responders was $32.2 \%(65 / 202)$ and $23.5 \%(8 / 34)$ in the NSAIDs responder and non-responder groups, respectively (univariate analysis [OR 1.54 [95\% Cl: 0.7 to 3.6$]$ ], $p=0.313$.

The multivariate logistic regression found the following independent factors of the TNFi response: gender [adjusted OR $(\mathrm{aOR})=2.9$ [CI95\%: 1.4-6.0], $\mathrm{p}=0.004$ ], age [aOR=0.9 [95\% Cl: 0.91 to 0.99], $\mathrm{p}=0.026$ ], $\mathrm{HLA}-\mathrm{B} 27$ status [aOR=2.5 [Cl95\%: $1.2-5.3$ ], $p=0.02$ ], ASDAS-CRP score [aOR=1.6 [95\% $\mathrm{Cl}: 1.1$ to 2.4], $\mathrm{p}=0.016$ ], and $\mathrm{MRI}$ sacroiliitis [aOR=2.0 [CI95\%: 1.0-4.2], $\mathrm{p}=0.054$ ]. Response to NSAIDs was not significantly associated to the response to the TNFi $[a O R=1.93[95 \% \mathrm{Cl}$ : 0.6 to 6.3$], p=0.275]$. The IPW aOR confirmed the non-association between NSAIDs good response and TNFi good response: 1.60 [CI95\%: 0.7-3.3], $p=0.20$. Conclusions: The good response to NSAIDs according to the Amor's criteria does not seem to be an independent predictive factor of a good response to the first TNFi in early axSpA patients.

Disclosure of Interest: None declared

DOI: 10.1136/annrheumdis-2018-eular.5839

\section{OP0023 \\ EFFECT OF ANTERIOR UVEITIS, PSORIASIS AND INFLAMMATORY BOWEL DISEASE ON DRUG- SURVIVAL FOR TNF-INHIBITORS IN ANKYLOSING} SPONDYLITIS

U. Lindström ${ }^{1}$, T. Olofsson ${ }^{2}$, S. Wedrén ${ }^{1}$, I. Qirjazo ${ }^{3}$, J. Askling ${ }^{1}$, on behalf of ARTIS. ${ }^{1}$ Rheumatology Unit and Clinical Epidemiology Unit, Department of Medicine, Karolinska Institutet, Stockholm; ${ }^{2}$ Department of Clinical Sciences, Lund Univeristy, Lund; ${ }^{3}$ Rheumatology Department, Linköping Univeristy Hospital, Linköping, Sweden

Background: Tumour necrosis factor inhibition (TNFi) is the mainstay treatment for ankylosing spondylitis (AS) with a high disease activity. Whereas disease activity and sex have been shown to affect drug-survival for TNFi in AS, the impact of typical AS-comorbidities, such as anterior uveitis, psoriasis and inflammatory bowel disease (IBD), on the drug-survival of TNFi in AS is less well understood.

Objectives: To determine the impact of comorbidity with anterior uveitis, psoriasis and IBD on drug-survival in patients with AS starting treatment with a first TNFi.

Methods: Swedish biologics-naïve patients with AS starting a 1 st TNFi July 1 2006 - December 31 2015, were identified in the Rheumatology Quality Register, and followed from treatment start until treatment discontinuation. Censoring occurred at the first of: December 31 2015, death, emigration, or loss of follow-up. Comorbidities, and potential confounders, were identified through linkage to six other national registers.

We calculated survival curves and hazard ratios (HRs) for each comorbidity and the risk of TNFi discontinuation. HRs were adjusted for sex, age, CRP, peripheral arthritis, type of TNFi and BASDAl at baseline. Additional models were also adjusted for other chronic morbidities (cardiovascular disease, affective disease, diabetes, malignancies, chronic lung disease and chronic kidney failure), and for socioeconomic status (length of education, household income, sick-leave, country of birth and civil status), respectively.

Results: 2577 patients ( $71 \%$ men) were identified, $27 \%$ had a previous history of anterior uveitis, $7 \%$ IBD and $6 \%$ psoriasis. A history of anterior uveitis was associated with a lower risk of TNFi discontinuation (HR 0.72; 0.62-0.83), whereas presence of psoriasis was associated with an increased risk (HR 1.48; 1.18-1.86). No association was found between presence of IBD and risk of TNFi discontinuation. Models adjusting for disease activity, morbidities, and socioeconomic status resulted in an attenuated association for psoriasis (table 1). The impact of each comorbidity on drug-survival is visualised in figure 1.

Abstract OP0023 - Table 1. HR for association between inflammatory comorbidities and risk of discontinuation of TNFi treatment in AS

\begin{tabular}{lcccc}
\hline Comorbidity & A & B & C & D \\
\hline Anterior uveitis & $0.72(0.62-0.83)$ & $0.71(0.60-0.84)$ & $0.72(0.61-0.85)$ & $0.75(0.62-0.90)$ \\
Psoriasis & $1.48(1.18-1.86)$ & $1.35(1.04-1.76)$ & $1.28(0.98-1.67)$ & $1.33(0.99-1.78)$ \\
IBD & $0.91(0.71-1.16)$ & $0.84(0.65-1.09)$ & $0.82(0.63-1.07)$ & $0.83(0.62-1.10)$ \\
\hline
\end{tabular}

A) univariable; B-D) adjusted for baseline measures; C) also adjusted for other morbidity and D) also adjusted for socioeconomic status.

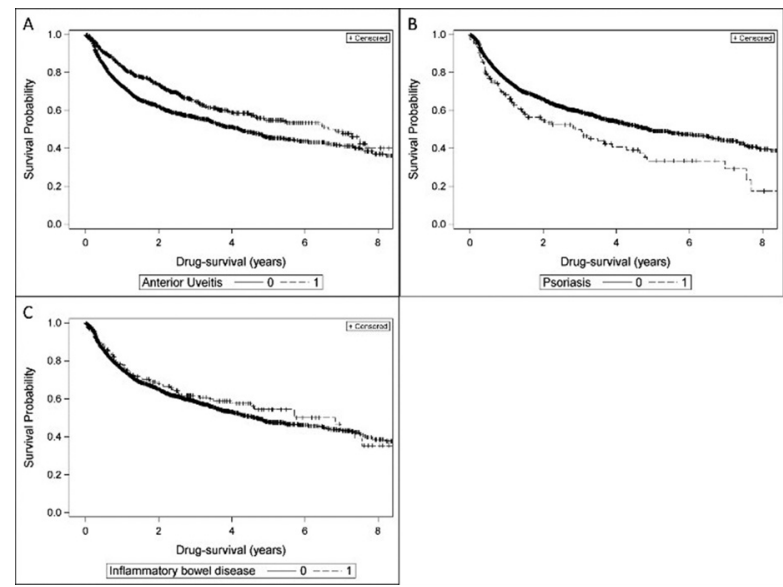

Abstract OP0023 - Figure 1 Survival probability (Kaplan-Meier plots) for persisting on a first-line TNFi, for patients with ankylosing spondylitis, dependant on having a history of (A) anterior uveitis, (B) psoriasis or (C) inflammatory bowel disease. 